\title{
La literatura peruana más allá de la frontera: la doble ausencia en los cuentos de Gunter Silva Passuni y Daniel Alarcón
}

\author{
Elisa CAIRATI \\ Università degli Studi di Milano
}

RESUMEN

El objetivo del presente trabajo es insertar las colecciones de cuentos Crónicas de Londres (2012) de Gunter Silva Passuni y War by Candlelight: Stories (2005) de Daniel Alarcón en el paradigma de la literatura migrante latinoamericana. Estos dos autores peruanos escriben desde tierras anglosajonas enfocando la complejidad del sujeto migrante en su doble estatuto epistemológico: el de emigrado e inmigrado, correspondiente a la "doble ausencia" teorizada por Sayad y concretizada en los textos en una intricada red de presencias falaces y ausencias irremediables. Gracias al conjunto de estrategias simbólicas y narrativas utilizadas por los autores, la experiencia literaria, bifronte y bicultural, aparece entonces como única posibilidad de ubicuidad y recomposición cultural en un sujeto en tránsito, en la frontera.

Palabras clave: literatura peruana contemporánea, literatura migrante, doble ausencia, "experiencia transmigráfica", heterogeneidad conflictiva.

Peruvian literature beyond the border:

the double absence in Daniel Alarcón and Gunter Silva Passuni's stories

\begin{abstract}
The present work aims to include the works Crónicas de Londres (2012) by Gunter Silva Passuni and War by Candlelight: Stories (2005) by Daniel Alarcón in the Latin American migrant literature paradigm. The two Peruvian authors writes from Anglo-Saxon lands focusing on the complexity of the migrant subject in his double epistemic condition, emigrate and immigrate, related to the "double absence" theorized by Sayad and materialized in the texts through an intricate system of false presences and irreparable absences. Thanks to the set of symbolic and narrative strategies used by the authors, the bicultural literary experience becomes the only possibility for ubiquity and for a cultural reset of a subject in transit, in the border.
\end{abstract}

Keywords: Peruvian contemporary literature, migrant literature, double absence, "transmigraphic experience", conflicting heterogeneity.

SUMARIO: 1. Literatura migrante peruana escrita desde el extranjero: Daniel Alarcón y Gunter Silva Passuni. 2. El paradigma de la doble ausencia y sus reflejos literarios. 3. Conclusiones: hacia una síntesis (literaria) no dialéctica de la experiencia migratoria. 
In the Borderlands you are the battleground where enemies are kin to each other; you are at home, a stranger, the border disputes have been settled the volley of shots have shattered the truce you are wounded, lost in action dead, fighting back;

Gloria Anzaldúa, "To live in Borderlands means you", Borderlands / La

Frontera

\section{Literatura migrante peruana escrita desde el extranjero: Daniel Alarcón y Gunter Silva Passuni}

La frontera se presenta cada vez más como símbolo definitorio de la condición del sujeto y del texto migrante. Las sugerentes dimensiones que ella genera, en tanto espacios de inclusión y espacios de exclusión, nuevas formulaciones identitarias y rearticulaciones de un discurso nacional apátrida y transnacional, se concretizan en el texto literario a través de recursos explícitos, ya sean temáticas y referencias directas, así como de herramientas implícitas, como el entramado intertextual, la estructura imagológica del relato y las posibilidades expresivas y lingüísticas.

Con este trabajo, por lo tanto, propongo enfocar el tema de los reflejos de la experiencia migratoria en el caso peculiar de la literatura peruana reciente escrita desde el extranjero. Mi objetivo es indagar el fenómeno de la literatura de la migración, que como señala Silvana Serafin (2014) es definido como "escritura migrante" (Moisan y Hildebrand, 2001; Chartier, 2002) o "literatura migrante" (Lebrun y Collès, 2007), y que Ana Ruiz Sánchez identifica como "literatura desterritorializada" (2005: 102), configurado como una narrativa errante, transnacional, íntima y al mismo tiempo plural, declinada en su especificidad latinoamericana ${ }^{1}$.

\footnotetext{
${ }^{1}$ El tema de la literatura migrante en el contexto latinoamericano está al centro de una profunda reflexión llevada a cabo por nombres importantes del hispanoamericanismo italiano. El número especial "Migración, diáspora, exilio en América Latina" de la revista de estudios culturales y literarios Altre Modernità de la Universidad Degli Studi de Milán, editado por Anamaria González Luna y Laura Scarabelli, recoge una muestra de estos trabajos y al mismo tiempo marca en hito en la sistematización del horizonte científico de los estudios acerca de la literatura migrante. En particular, el ensayo "Letteratura migrante. Alcune considerazioni per la definizione di un genere letterario" de Silvana Serafin (2014: 1-17) indaga los orígenes y las características de la literatura de la migración, en particular
} 
En particular, propongo analizar el caso de dos autores peruanos que escriben desde la condición de migrantes en el mundo anglosajón. Se trata de Gunter Silva Passuni (Chanchamayo, 1976), residente en el Reino Unido, y Daniel Alarcón (Lima, 1977), radicado en Estados Unidos. En sus obras encontramos huellas de los que Daniel Mesa Gancedo (2012: 11) define "experiencia transmigráfica", es decir el proceso de subjetivación, reelaboración y escritura de la experiencia migratoria. Una experiencia, entonces, que no solo se refleja necesaria e inevitablemente en el texto literario, sino que se completa a través de él, gracias a la opción de la escritura. Como afirma Ana Ruiz Sánchez,

todo texto literario es parte de un proyecto estético que elige la representación artística para dar respuesta a una pregunta -formulada expresamente en una minoría de casos- pero siempre existente. Escribir para entendernos a nosotros mismos, para entender nuestra sociedad, o los cambios a los que ella nos aboca, para tratar de encontrar razón a lo inexplicable o describir lo inconcebible, o volver a nombrar lo que se convirtió en innombrable... ${ }^{2}$ (2005: 102)

En el presente artículo, mi objetivo es presentar una serie de correspondencias entre las colecciones de cuentos Crónicas de Londres, publicada en Lima en 2012, por Gunter Silva Passuni y War by Candlelight: Stories publicado en Nueva York en 2005 por Daniel Alarcón, centrando la reflexión en la dicotomía implícita del estatuto epistemológico del migrante, que es al mismo tiempo inmigrante y emigrante, y en las modalidades a través de las cuales esta doble dinámica está representada en los textos.

En primer lugar, considero imprescindible subrayar tres aspectos significativos que recorren transversalmente las dos obras en cuestión: el problema de la lengua literaria, la recurrencia del género del cuento y del relato, y la ficcionalización de la experiencia migratoria como narrativa autoficcional.

Tan solo observando los títulos podemos deducir que los autores presentan trayectorias opuestas con respecto a la cuestión de la lengua literaria: por un lado, para Gunter Silva Passuni la lengua literaria coincide con la lengua madre, o sea el castellano, mientras que, por otro lado, Daniel Alarcón elige escribir en la lengua

en el continente latinoamericano, argumentando la autonomía de esta producción literaria como género específico, interdisciplinario y prolífico. Asimismo, Ana Ruiz Sánchez, en su trabajo sobre la relación entre desterritorialización y literatura en la era de la globalización, señala la necesidad de reconocer la autonomía del corpus relativo a la "literatura desterritorializada", de exilio y migración, definiendo características y parámetros de esta nueva "topografía literaria" (2005: 108-111).

${ }^{2}$ Inevitable, a este propósito, resulta la referencia al análisis de Fernando Reati Nombrar lo innombrable: violencia política y novela argentina 1975-1985 (1992), sobre la literatura de la dictadura argentina. 
adquirida con la migración, es decir el inglés. Efectivamente, el paradigma de la literatura de migración, como recuerda Paolo Proietti (2000: 96), posibilita "una producción literaria originada por los migrantes, lejos de su propio país, a veces en otro idioma, lejos de la lengua madre" (la traducción es mía). Agrega Ana Ruiz: Si el país de acogida tiene otra lengua, esta literatura será bilingüe, es decir, encontraremos obras tanto en la lengua materna de los inmigrantes / exiliados como en la lengua del país de acogida, pues parte de los inmigrantes / exiliados deciden realizar en dicha sociedad y, sobre todo, en dicha lengua su proyecto de vida (2005: 105).

A este propósito, resulta particularmente interesante el dato biográfico: por un lado, para Gunter Silva Passuni la experiencia migratoria se configura como posibilidad de desarrollo de proyectos personales en edad adulta, mientras que, por otro lado, para Daniel Alarcón, representa una etapa de la edad infantil, de hecho sus padres migraron para alejarse de la convulsa realidad peruana de los años 80 , determinando para su hijo y futuro escritor una escolarización exclusivamente estadounidense. Sin embargo, no obstante esta migración hacia el sistema cultural anglosajón, ambos autores vuelven a reproducir, aunque con códigos lingüísticos y modalidades estilísticas distintas, la referencia intensa y constante a la realidad peruana, motivada por la búsqueda de una identidad nacional fragmentada.

Esta 'peruanidad' es denunciada por distintos factores. En primer lugar por las temáticas: el migrante peruano en Europa o en Estado Unidos, así como las vicisitudes históricas del Perú contemporáneo, incluyendo la migración interna de los Andes a las ciudades y la reciente y dramática experiencia del Conflicto Armado Interno. En segundo lugar por la focalización narrativa, que prefiere narradores latinos, en su mayoría peruanos, muy a menudo nostálgicos. Sin embargo cabe subrayar que esta 'peruanidad' es desvelada más bien por un tácito entramado intertextual que remite inevitablemente a la forma literaria del cuento. En particular, las obras analizadas muestran un constante diálogo con la producción peruana del neorrealismo urbano, que tuvo su momento de apogeo con la Generación del 50: una especie de "picaresca urbana" (Chavarría Alfaro, 2010) en la que el narrador se mueve dentro de un espacio -el espacio urbano justamente- claustrofóbico y violento, símbolo contrapuntístico de progreso y aniquilamiento. Los mismos autores identifican como modelos de referencia a personajes de la envergadura de Julio Ramón Ribeyro, Oswaldo Reynoso, Carlos Eduardo Zavaleta y Luis Loayza, integrantes de la Generación del 50, con los cuales, gracias a los magistrales ejemplos de la tradición argentina, el cuento se consagra como forma narrativa autónoma también en Perú. Asimismo, cabe subrayar que la misma Generación del '50 se vio influenciada por la narrativa norteamericana, y en particular por las obras de Hemingway, Faulkner y Dos Passos, escritores e intelectuales entregados a la observación y a la representación de la realidad social a quienes debemos la introducción de innovadoras estrategias literarias en novelas y relatos. En efecto, observando la estructura textual, se nota que los cuentos de Silva Passuni y Alarcón 
comparten características formales como el desarrollo no lineal del relato -realizado a través de la simultaneidad de espacios y lugares, así como con la fragmentación temporal de la trama-, y la relativización de los puntos de vista -lograda gracias a la focalización narrativa en muchos casos oscilante entre un narrador-personaje y una voz omnisciente, que recurre al discurso indirecto libre-. Rasgos, estos, introducidos en la narrativa peruana propiamente por los escritores del 50 y que se podrían analizar, en cierta medida, como línea de intertextualidad.

Resulta particularmente interesante, además, que la forma del cuento esté al servicio de la representación de la identidad migrante: las colecciones de relatos de estos autores, en efecto, se configuran como un catálogo de las mil caras del latino invisible en tierras anglosajonas, y del serrano en el tejido urbano, que podríamos interpretar como un caleidoscópico fraccionamiento del yo literario. Cuando se descubren sus nombres, los personajes-narradores de Silva Passuni son Diego, Felipe, Fernando, Joaquín, Santiago. Todos migrantes, trabajadores ocasionales, en algunos casos inmersos en otro tipo de precariedad, es decir la enseñanza. En algunos cuentos, sin embargo, la voz narrativa es tan solo una estrategia de focalización para vehicular la mirada hacia otro migrante, como en el caso de Jorge, argentino obligado a pedir limosna propinando a su familia la utopía de un buen trabajo, o de Pablo y Enrique, jóvenes concertistas que consideran el viaje a Europa como la posibilidad de una verdadera iniciación. Alarcón utiliza la misma estrategia: sus personajes son niños, jóvenes y adultos que se mueven en el caos y en la violencia ciudadana de un Perú marcado por el signo de guerra, como en los relatos "Flood", "City of Clowns", "Lima, Peru, july 28, 1979", "El señor va montado sobre una nube veloz", "The visitor", "War by candlelight" y "A science for being alone". O bien son peruanos migrados a Estados Unidos buscando la realización del 'sueño americano' y caídos en una especie de mecanismo aniquilador, repetitivo y estático, de perspectivas inciertas, como en "Absence" y "A strong dead man".

Por lo tanto, parece legítimo preguntarse en qué medida la ficcionalización de la experiencia migratoria, interna y externa, pueda funcionar como autobiografía especular, traducida en narrativa autoficcional. El problema es todavía más complejo: no se trata de una autobiografía única y privada, sino de un cuento plural,

\footnotetext{
${ }^{3}$ Es interesante observar que en la traducción al castellano de la obra de Alarcón (2006, Guerra a la luz de las velas. Madrid: Alfaguara. Trad. de Jorge Cornejo) el título de este cuento aparece como "Huayco", término peruano, difundido también en otros países andinos, que indica un derrumbe de barro y rocas causado normalmente por una aluvión. En este contexto el análisis no se centrará en las estrategias de traducción, tarea que sin duda daría lugar a reflexiones interesantes. Nos limitaremos, por tanto, a señalar casos significativos, agregando, además, que la versión traducida incluye dos textos que no forman parte primera edición de la versión original: "Florida" y "El Señor va montado sobre una nube veloz".
} 
propio de la comunidad migrante entera. Efectivamente, en ambas obras, a nivel narratológico, se puede notar una predominancia de la focalización interna, con una narración en primera persona. Un yo-protagonista que asume, siempre y exclusivamente, el rostro de un hombre que ha vivido la experiencia del desarraigo en carne propia y que ahora tiene que enfrentarse a una realidad hostil. Es interesante que, en cambio, la figura femenina quede en el telón de fondo y siempre aparezca como un personaje secundario. El uso de la focalización externa, con una narración omnisciente en tercera persona, es reducido -Silva Passuni recurre a esta herramienta tan solo en un cuento sobre nueve de la colección, mientras que Alarcón en cuatro sobre nueve relatos- y parece estar limitado a cuentos en los que se encierra una experiencia atomizada, es decir cuentos en los que el protagonista migrante ya no está solo, sino que lleva consigo una red de relaciones que lo acompañan incluso durante el viaje, dando y restituyendo vida a la parte de identidad abandonada con el desplazamiento.

\section{EI paradigma de la doble ausencia y sus reflejos literarios}

Frente a lo expuesto, propongo una crítica de los textos basadas en la trayectoria de los estudios de Sayad (2002) en torno a la subjetividad del migrante. Sayad caracteriza el migrante como 'inmigrado' que es ante todo 'emigrado' y, por tanto, sujeto ya íntimamente dúplice e incoherente, atopos en sentido platónico, es decir inclasificable, sin y afuera del tiempo. Por lo tanto, el migrante es una figura subversiva, que escapa de dos o incluso más sistemas culturales, políticos y sociales, caracterizada en negativo, en base a una "doble ausencia" (Sayad, 2002): ausencia en la propia patria, en el lugar de origen, y ausencia en la sociedad de acogida, en donde el inmigrado resulta un elemento invisible y ajeno. Este sujeto fragmentado y "desterritorializado" (García Canclini, 1990) percibe entonces un territorio multiplicado, e igualmente ajeno, donde las experiencias resultan totalmente desconectadas entre sí debido a la discontinuidad simbólica de los sistemas culturales. El discurso del migrante, por tanto, no realizará una síntesis armónica de estas experiencias, sino más bien un contrapunteo entre presencias falaces e ilusorias y ausencias inevitables. Es interesante observar cómo esta doble ausencia, y entonces cómo el discurso del migrante, se refleje y se reconstruya en la representación literaria, a través de estrategias narrativas y temáticas que revelan, en realidad, el protagonismo de un verdadero 'cuento de ausencias'. Dice Alarcón, precisamente en el cuento "Absence":

Leaving is no problem. It's exciting actually; in fact, it's drug. It's the staying gone that will you. This is the handed-down wisdom of the immigrant. You hear it from the people who wander home, after a decade away. You hear about the euphoria that passes quickly; the new things that lose their newness and, soon after, their capacity to amuse you. Language is bewildering. You tire of exploring. Then the list of things you miss multiplies beyond all reason, nostalgia 
clouding everything: in memory, your country is clean and uncorrupt, the streets are safe, the people universally warm, and the food consistently delicious. The sacred details of your former life appear and reappear in strange iterations, in a hundred waking dreams. Your pockets fill with money, but your heart feels sick and empty. (2005: s.n.)

En los textos analizados encontramos, de hecho, presencias que no realizan la integración del sujeto, percibido principalmente como inmigrado. En primer lugar, la ciudad, la 'urbe', es presencia que se vuelve personaje: para Silva Passuni se trata de Londres, y en el caso del último texto, que es una verdadera crónica literaria, en cambio estamos en París, mientras que para Alarcón se trata de una Lima digna de las mejores representaciones del realismo urbano peruano. Son ciudades hostiles que desorientan, inmersas en una geografía desarticulada. Josefina Ludmer (2010) define la "isla urbana" como el emblema de la ruptura del contacto con la naturaleza en sentido genérico, pero también, y sobretodo, con la naturaleza humana. En "I live by the River", Silva Passuni dibuja un paisaje londinense íntimo y aterrador: "Londres te disuelve, te devora si no conoces sus calles, si no tienes trabajo, eres un fantasma que hace venir a otros fantasmas" (2012: 83). En la misma línea se mueve Alarcón, que personaliza la ciudad de Lima como una entidad "gritty and dangerous", que puede "play tricks", y enseñar "to dance salsa. To drink and smoke, to fight, fuck, and steal" (2005: s.n.). Además, en la urbe anglosajona asistimos a la homogeneización de la identidad latina, cuyas distintas nacionalidades están reemplazadas por el estereotipo: así en el cuento "La foto perfecta" de Silva Passuni, una muchacha española pide al personaje-narrador que reclute a otros 'latinos', entre los cuales un connacional peruano, un boliviano y un colombiano, para que todos, pese a sus diferencias identitarias, finjan ser sus familiares en su boda (2012: 22-23); o bien, en el cuento "Ausencia" de Alarcón, Leah, una chica americana, presenta a Wari, el protagonista pintor peruano que se encuentra en Estados Unidos, un supuesto connacional peruano vendedor ambulante de artesanía andina, que en realidad descubrimos ser ecuatoriano (2005: s.n.).

Los narradores se mueven por tanto en el solo espacio urbano, en el que a menudo tropiezan en una representación sintética y sincrética de su identidad. En filigrana, en todos los cuentos, se lee de hecho la búsqueda obsesiva de la identidad, a menudo materializada frente al narrador como una realidad alterada. A nivel simbólico, estas figuras revelan una alteración del imaginario cultural del país de acogida, contaminado por la identidad latina del migrante. Vemos entonces que, en "Vino tinto en Mac Donalds", Silva Passuni articula el relato en torno a una relación de identificación entre Felipe, el narrador-personaje -migrante ilegal en busca de una "novia for cash" como única posibilidad para obtener la ciudadanía- y la imagen del 'vino tinto' que Felipe lleva consigo y añade a la Coca-Cola durante un almuerzo en Mac Donald (2012: 48-55). 
Asimismo en "Homesick", Silva Passuni destaca la imagen del "limpiacristales" como etapa obligatoria e imprescindible de la migración latina en tierras anglosajona: "La limpieza es la profesión de los latinos, contesté, cuando me preguntaron por qué limpiaba ventanas para vivir" (2012: 63). La misma trayectoria es retomada por Alarcón en "Absence": "In America, you can sweep floors and make money, if you're willing to work -you are willing to work, arent'you, Wari? Yes, I am. At anything? Outdoor work? Lifting, carting, cleaning? Anything" (2005: s.n.). En este último cuento, además, surge imprevista, al principio de la narración, una secuencia de imágenes concatenada de manera casi cinematográfica, que describe un carnaval sincrético: "On the train, he'd seen break dancing and heard Andean Flutes. He'd watched a Chinese man play a duet with Beethoven on a strange electronic harmonica. In Times Square, a Dominican man dances a frenetic merengue with a life-size doll" (2005: s.n.). Son voces de un horizonte transculturado, de una identidad en busca de sí misma en tierras extranjeras.

En contrapunto a estas presencias irresueltas, encontramos sofocantes ausencias, que caracterizan, en primer lugar, el discurso del emigrado. La ausencia de la patria es desvelada no solo por la nostalgia hacia las propias raíces, hacia un país idealizado donde todo parece tener un orden -en contraposición, justamente, con el des-orden cultural proyectado por las imágenes alternadas mencionadas-, sino más bien por el uso de las variaciones lingüísticas, y en particular, de la vertiente diafásica. El narrador-personaje, de hecho, utiliza un lenguaje estándar, sin influjos regionales, que sin embargo revela su pertenencia geográfica al entrar en contacto con un interlocutor perteneciente a su misma intimidad familiar o nacional, dejando amplios espacios al discurso directo. La lengua se vuelve pues una herramienta relacional, reveladora de las posibilidades de expresión al interno de un mismo código cultural. Ejemplar es el caso de un fragmento de Alarcón, en el que los regionalismos andinos traspasan las fronteras y aparecen en un narrativa escrita en inglés: "When she was out of earshot, Fredy turned to Wari. -Don't ask me for work, compadre -he said, frowning. -It's hard enough for me. Wari was taken aback. -Who asked you for work? I've got work, cholo. -Sure you do" (Alarcón, 2005: s.n.).

En cambio, en el caso de contactos con un interlocutor extranjero, el sujeto migrante se encierra en la incomunicabilidad, arrinconando su interioridad en el espacio narrativo y dejando espacio al discurso indirecto, a menudo cercado a su modalidad libre: "How long will you stay $I$ do not know. HowlongwillyoustayIdonotknow" (Alarcón, 2005: s.n.).

Además, cabe subrayar dos estrategias, distintas pero en cierto sentido coincidentes, a través de las cuales vuelve a subrayarse la ausencia de la patria o del país de origen. En los cuentos de Silva Passuni, de hecho, se nota un énfasis emblemático hacia las relaciones amorosas, en las que mujeres extranjeras eligen las reglas del juego y se sirven de jóvenes migrantes latinos para sus fines: en "Lottie", una mujer madura muy rica atrae a un joven camarero peruano, con el cual 
improvisamente decide vivir una relación loca y fugaz, un matrimonio fingido de pocas semanas; en "Vino tinto en Mac Donalds" Kloe acepta casarse por dinero con Felipe, migrante con papeles irregulares pero, tras haber recibido la primera parte del dinero, desaparece y el cuento se cierra con una escena en que hay policías que están allí, listos para detener a Felipe y la sonrisa agria de Kloe en el fondo; en "Homesick", la Señora Sherwood, dueña de casa, pide a Santiago, colombiano limpiacristales empleado en su casa, que le haga un pequeño favor, sin añadir explicaciones. Como venganza contra el marido, la Señora Sherwood tiene una relación sexual con Santiago, y queda todo grabado, hecho que, obviamente, va a complicar la vida del protagonista.

Los cuentos de Alarcón, en cambio, están marcados por el signo común de la guerra: no una guerra cualquiera, sino el Conflicto Armado Interno Peruano, cada vez enfrentado a través del punto de vista de un miembro del partido comunista Sendero Luminoso. El dato revela el interés del autor hacia las dinámicas de la realidad convulsa de aquellos años, que el autor no vivió porque ya había emigrado, y sin embargo, representa un tema central en la poética del autor. La crítica ha hablado mucho de Alarcón refiriéndose justamente a la producción de literatura de ficción en torno al tema del terrorismo, pero en mi opinión este tema no revela tan solo un interés hacia el pasado reciente de su país de origen, sino que es un pretexto para subrayar, en realidad, diversos momentos y ámbitos en los que se ha manifestado, en Perú, un momento de brusco y violento cambio. En este sentido, Alarcón se ocupa también e inevitablemente de la migración interna, que, con la industrialización, vio ciudadanos de las provincias llegar en frotas a las ciudades, y en particular, a la capital. En el cuento "Lima, Peru, july 28, 1979", el autor pinta un fresco de la realidad limeña a finales de los años 70, época en la que las manifestaciones terroristas anticapitalistas de Sendero Luminoso llegaron hasta la capital. El relato, en primera persona, propone como protagonista a un joven arequipeño que se mudó a Lima por razones de estudio y acabó acercándose a las visiones filosófico-políticas del 'Pensamiento Gonzalo': "Lima was known then for swallowing lives, drawing people from their ancestral homes, enveloping us in her concrete and noise. I became one of those people. I saw the city and felt its chaos and its energy; I couldn't go home" (2005: s.n.).

En este sentido, Sendero se vuelve símbolo de la voluntad de emancipación vivida a través de la migración y el apego a ideales políticos revolucionarios- luego frustrada por la contaminación urbana, y por el mecanismo inevitable de la guerra, que, fundiéndose con la ciudad misma, detiene al individuo.

\section{Conclusiones: hacia una síntesis (literaria) no dialéctica de la experiencia migratoria}

En conclusión, la literatura de migración se vuelve un espacio de síntesis, uno de los "espacios en medio" de los que habla Homi Bhabha, destinado a la reformulación de cuestiones identitarias (Neri, 2001: 414). A través de la palabra 
escrita, Silva Passuni y Alarcón intentan realizar una posibilidad de ubicuidad nunca lograda: los cuentos muestran, de hecho, finales abiertos y metafóricos como en el ya mencionado "Absence" de Alarcón, que se concluye con un brazo que indica, a lo lejos, el lugar donde se encontraban las Torres Gemelas, elemento del paisaje urbano elegido como símbolo de muchas otras ausencias-; mecanismos narrativos agarrotados o circulares - de los que es ejemplo perfecto el primer cuento de la colección de Silva Passuni, "La foto perfecta", en que una foto, imagen que abre y cierra el texto, representa la única posibilidad de efímera felicidad en un sistema de indiferencia e incomunicabilidad-; la reformulación constante de la dicotomía centro/periferia -puesto que el discurso del migrante es por definición des-centrado-, y la doble temporalidad que se reflejan en la alteración del ritmo del relato -analepsis, prolepsis y flashback insistentes-.

Por lo tanto, la identidad migrante, además de estar definida por una doble ausencia, encierra, como recuerda Antonio Cornejo Polar, una síntesis no dialéctica de la experiencia. El migrante es un sujeto "subalterno sin remedio" insertado en la "heterogeneidad conflictiva" y en el "espacio abierto y dialéctico" de la frontera como signo originario. Un sujeto en tránsito, entre 'viejos' y 'nuevos' mundos, que hace de la migración, y entonces de la frontera, su condición existencial. Estas narrativas, igualmente erráticas, dibujan entonces nuevas cartografias literarias, en las que el signo lingüístico ya no se considera como único y excluyente factor de pertenencia y catalogación. Por lo tanto, ellas identifican una literatura autónoma, o, en palabras de Josefina Ludmer, "posautónoma", fronteriza, según Cornejo Polar "bifronte y esquizofrénica", y sin embargo caracterizada por la misma voluntad de "mirar hacia dentro" a través de esta literatura "de fuera" (Caudet, 2008: 21).

\section{BIBLIOGRAFÍA}

ALARCón, Daniel.

2006 Guerra a la luz de las velas. Madrid: Alfaguara.

2007 Lost City Radio. New York: HarperCollins.

2007 Radio Ciudad Perdida. Lima: Alfaguara.

2005 War by Candlelight: Stories. New York: HarperCollins.

Alarcón, Daniel y Alvarado, Sheila.

2010 Ciudad de payasos. Lima: Alfaguara.

ANZALDÚA, Gloria.

1987 Borderlands / La frontera. San Francisco: Aunt Lute.

1997 "Vivere nelle Terre di frontiera significa che...", en Mario Maffi, Voci di frontiera. Scritture dei Latinos negli Stati Uniti. Milano: Feltrinelli, pp. 49-50. 
CAUDET, Francisco.

2008 "De qué hablamos cuando hablamos de literatura de exilio republicano de 1939?", en Primer Congreso Internacional de Literatura y Cultura Españolas Contemporáneas, La Plata, 1 al 3 de octubre de 2008, pp. 1-25. Disponible en: http://www.fuentesmemoria.fahce.unlp.edu.ar/trab_eventos /ev.305/ev.305.pdf [Consultado el 28 de diciembre de 2013].

CHARTIER, Daniel.

2002 "Les origines de l'écriture migrante. L'immigration littéraire au Québec au cours des deux derniers siècles", en Voix et images, vol. XXVII, núm. 2, pp. 303-316.

CHAVARRÍA AlFARO, Gabriela.

2010 "Literatura y subjetividades migrantes", en Revista Ixchel, Vol. 2, 2010, s.n. Disponible en: http://www.revistaixchel.org/attachments/093_Literatura $\% 20 y \% 20$ subjetividades\%20migrantes.pdf [Consultado el 28 de diciembre de 2013].

CORNEJO POLAR, Antonio.

1996 "Una heterogeneidad no dialéctica: sujeto y discursos migrantes en el Perú moderno", en Revista Iberoamericana, vol. LXII, núm. 176177, julio-diciembre, pp. 837-844.

GARCÍA CANCLINI, Néstor.

1990 Culturas híbridas. Estrategias para entrar y salir de la modernidad. México: Grijalbo.

KANELLOS, Nicolás (ed.).

2002 En otra voz: Antología de la literatura hispana de los Estados Unidos. Houston: Arte Público Press.

2007 "Panorama de la literatura hispana de los Estados Unidos", en ParaleloSur. Revista de Literatura, Dossier, núm. 5. Disponible en: http://www.paralelosur.com/revista/revista_dossier_021.htm [Consultado el 28 de diciembre de 2013].

LEBRUN, Monique y Luc COLLÈs.

2007 La littérature migrante dans l'espace francophone. BelgiqueFrance-Québec-Suisse: Cortil-Wodon, E.M.E \& Intercommunications S.P.R.L.

LUDMER, Josefina.

2010 Aqui América latina. Una especulación. Buenos Aires: Eterna Cadencia.

MAFFI, Mario.

2009 "I fantasmi e i corpi. Breve excursus sulla letteratura dei Latinos negli Stati Uniti”, en Altre Modernità, núm. 2, octubre, pp. 46-58. 
1997 Voci di frontiera. Scritture dei Latinos negli Stati Uniti. Milano: Feltrinelli.

MARCELLES, Eduardo.

2003 "La literatura del exilio: escritores latinoamericanos en Nueva York", en Revista Virtual de Cultura Iberoamericana. Disponible en:

http://www.qcc.cuny.edu/foreignlanguages/rvci/marcelesliteratura.h tml [Consultado el 28 de diciembre de 2013].

MeSA GANCEDO, Daniel.

2012 Novísima relación. Narrativa Amerispánica actual. Edtudio, selección y materiales complementarios. Zaragoza: Letra Última.

MOISAN, Clément y Renate HILDEBRAND.

2001 Ces étrangers du dedans. Une histoire de l'écriture migrante au Québec (1937-1997). Québec: Nota bene.

MORA, Vicente Luis.

2011 "La identidad migrante y su reflejo en los libros sobre inmigración en los Estados Unidos", en Impossibilia, núm. 2, octubre, pp. 48-62.

NERI, Francesca.

2002 "Multiculturalismo, Estudios Postcoloniales y Descolonización", en Armando Gnisci (ed.), Introducción a la Literatura Comparada, Barcelona: Crítica, pp. 391-439.

PROIETTI, Paolo.

2000 Lontano dalla lingua madre. Roma: Armando Editore.

REATI, Fernando.

1992 Nombrar lo innombrable: violencia politica y novela argentina 1975-1985, Buenos Aires: Legasa.

RUIZ SÁNCHEZ, Ana.

2005 "Desterritorialización y literatura. Literaturas de exilio y migración en la era de la globalización", en Migraciones y Exilios, núm. 6, pp. 101-112.

SAYAD, Abdelmalek.

2002 La doppia assenza. Dalle illusioni dell'emigrato alle sofferenze dell'immigrato. Milano: Raffaello Cortina Editore.

SERAFIN, Silvana.

2014 "Letteratura migrante. Alcune considerazioni per la definizione di un genere letterario", en Altre Modernità, núm. especial "Migración, diáspora, exilio en América Latina", abril, 1-17. Disponible en: http://riviste.unimi.it/index.php/AMonline [Consultado el 28 de junio de 2014].

SILVA PASSUNI, Gunter.

2012 Crónicas de Londres. Cuentos y Relatos. Lima: Atalaya Editores.

2013 Homesick, Miami: Sub-Urbano Ediciones. 
STECHER, Lucía.

2010 "Daniel Alarcón y la re-invención literaria del Perú a la luz de la distancia", Reseña de Radio Ciudad Perdida y Guerra a la luz de las velas de Daniel Alarcón, Editorial Alfaguara, Lima, 2006-2007, en Letrasenlínea. Disponible en: http://www.letrasenlinea.cl/ ?p=411 [Consultado el 28 de diciembre de 2013].

SUB-URBANO.

2013 "A Estados Unidos suele emigrar la gente pensando que terminarán actuando en una película de Hollywood. Entrevista con el escritor Silva Passuni”, en Suburbano, Revista Cultural Miami. Disponible en http://sub-urbano.com/a-estados-unidos-sueleemigrar-la-gente-pensando-que-terminaran-actuando-en-unapelicula-de-hollywood-entrevista-con-el-escritor-gunter-silvapassuni/ [Consultado el 28 de diciembre de 2013].

TALA, Pamela.

2011 "Imaginarios de la migración/Migraciones del imaginario: Ausencia de Daniel Alarcón", en Confluenze. Rivista di studi iberoamericani, vol. 3, núm 1, pp. 164-173.

YUSHIMITO DEL VALLE, Carlos.

2006 "Emigración: un tema postergado. A propósito de Guerra a la luz de las velas de Daniel Alarcón", en Proyecto Patrimonio. Disponible en: http://www.letras.s5.com/da241006.htm [Consultado el 28 de diciembre de 2013]. 